rev.relac.int.estrateg.segur.7(2):193-219,2012

\title{
LA SEGURIDAD INTERNACIONAL EN LA PROYECCIÓN DE CHILE HACIA EL CONO SUR: ¿DESDE LA DOCTRINA DE LA SEGURIDAD NACIONAL HACIA LA CONSTRUCCIÓN DE COMUNIDADES DE SEGURIDAD O LA EMERGENCIA DE LA SECURITIZACIÓN?*
}

\author{
Cristian Ovando Santana**
}

\section{RESUMEN}

En este artículo se plantea que la evolución de la realidad internacional del Cono Sur de América en el campo de la seguridad, a partir de mediados de la década del 70, es interpretada por la doctrina de la seguridad nacional y posteriormente por aproximaciones reflectivistas moderadas. Estas últimas, al inicio de los 90, se comienzan a tomar en cuenta en respuesta a los desafíos de la región en el marco de la internacionalización y democratización de las unidades políticas que la componen. Se trata del uso de categorías tales como comunidades de seguridad y autonomía relacional, junto a los aportes de la seguridad humana. No obstante, también destacamos un replanteamiento de las corrientes tradicionales a partir de la vigencia de aproximaciones realistas,

* Resultado del proyecto de investigación titulado "Diagnostico de la dinámica transfronteriza chileno boliviana presente en la región de Tarapacá: aproximación desde los actores clave". Patrocinado por la dirección general de investigación de la Universidad Arturo Prat, Iquique, Chile. Cód.: DI 0066-09.

** Doctorando en Estudios Internacionales, Universidad del País Vasco. Becario CONYCIT y Académico del Instituto de Estudios Internacionales de la Universidad Arturo Prat, Iquique, Chile.

Correo electrónico: covando@unap.cl 
las que plantean la securitización de algunos fenómenos, sobre todo los referidos a la construcción de amenazas en torno a la instrumentalización de litigios fronterizos pendientes.

Palabras clave: Cono Sur, Doctrina de Seguridad Nacional, comunidades de seguridad, securitización, comunidades epistémicas.

\title{
INTERNATIONAL SECURITY IN CHILEAN PROJECTION IN THE SOUTHERN CONE: ¿FROM THE NATIONAL SECURITY DOCTRINE TOWARDS BUILDING SECURITY COMMUNITIES OR THE EMERGENCE OF SECURITIZATION?
}

\begin{abstract}
In this paper we suggest that the evolution of the international situation in the Southern Cone of America in the security field, from the mid-seventies, has been interpreted by the national security doctrine and, subsequently, by moderate constructivist approaches. In the early nineties, the latter began to receive more attention as way of addressing the regional challenges in a context of internationalization and democratization of the political entities in the region. This is reflected in the use of concepts as security communities and relational autonomy, as well as the contributions of human security approaches. However, we also emphasize a rethinking of the traditional perspectives with the relevance of the realist approaches, and those advanced by the securitization of some issues, in particular those regarding the threat building related to the instrumentalization of enduring disputes over borders.
\end{abstract}

Key Words: Southern Cone, the national security doctrine, security communities, securitization, epistemic communities.

\section{A SEGURANÇA INTERNACIONAL NA PROJEÇÃO DO CHILE PARA O CONE SUL: DESDE A DOUTRINA DE SEGURANÇA NACIONAL PARA A CONSTRUÇÃO DE COMUNIDADES DE SEGURANÇA OU A EMERGÊNCIA DA SECURITIZAÇÃO?}

\section{RESUMO}

Neste artigo, sugerimos que a evolução da situação internacional no Cone Sul da América no âmbito da segurança, a partir de meados dos anos 70, é interpretada pela doutrina de segurança nacional e, posteriormente, por abordagens refletivistas moderadas. No começo dos anos 90, estas últimas começam a ser levadas em conta como resposta aos desafios da região no contexto da internacionalização e democratização das unidades políticas que as compõem. Trata-se do uso de categorias como comunidades de segurança e autonomia relacional, juntamente com os aportes da segurança humana. No entanto, também destacamos um repensar das correntes 
tradicionais a partir da vigência de aproximações realistas, as quais levantam a questão da securitização de certos fenômenos, especialmente aqueles relacionados à construção de ameaças em torno da instrumentalização dos litígios fronteiriços por resolver.

Palavras-chave: Cone Sul, doutrina de segurança nacional, comunidades de segurança, securitização, comunidades epistêmicas.

\section{INTRODUCCIÓN}

En este trabajo abordamos algunas de las teorías que han inspirado en el Cono Sur de Sudamérica -particularmente el caso chileno- las políticas exteriores referidas a la seguridad. Destacamos que la evolución de dichas teorías, sus continuidades, cambios y reinterpretaciones obedecen tanto a los cambios del contexto internacional como a la persistencia de comunidades epistémicas abocadas al estudio sistemático del fenómeno de la seguridad internacional.

El giro en las aproximaciones de seguridad desde corrientes realistas hacia aproximaciones que promueven el cambio pacífico y que tienen como objetivo dimensiones referidas a la "comunidad internacional" e individuo en desmedro del Estado, se debería, entre otras razones, a la influencia de comunidades epistémicas (Adler y Haas, 2003; Peteres, 2003); estos enfoques abogaban por una mirada superadora del realismo, en el sentido de que este último enfatizaba sobre las aprehensiones de las fronteras contiguas y en un denominado enemigo interno, donde sobresalían amenazas sistemáticas a la seguridad (Atkins,1990). A partir de 1990, estos aspectos se hicieron obsoletos, aunque reinterpretados a la luz de nuevas amenazas a la seguridad, como es el caso de la ingobernabilidad, el narcotráfico, el terrorismo, la pobreza, el deterioro ambiental, etc. (Tickner, 2008; Griffiths, 2008), y por la persistencia de la percepción de amenazas en torno a rivalidades fronterizas o su instrumentalización (Fuentes, 2008; Leyton, 2005). En definitiva, estas variantes constructivistas apuntan a una relación más cooperativa en el ámbito de la seguridad presente en el Cono Sur, dando cuenta, además, de los cambios del sistema internacional en la pos Guerra Fría (Flennes, 2003; Fuch, 2006).

Estos cambios implicaron que la definición de nuevas amenazas enfrentara a dos retos, uno, el aumento de la inseguridad, producto de nuevas amenazas difusas y difícil de distinguir una de otra; y una segunda, relacionada con la persistencia de enfoques de estudios de seguridad tradicionales (García y Rodrigo, 2008, p. 205).

La ineficacia de los enfoques tradicionales -abocados a la integridad territorial y a la amenazas internas construidas ideológicamente- y el aumento de la inseguridad, plantean la necesidad de cambiar la orientación desde el Estado y su dogma persistente de la integridad territorial hacia la seguridad del individuo y las comunidades, incluyendo la rehabilitación de la seguridad colectiva en términos jurídicos eficaces, adaptando su institucionalidad hacia estos nuevos desafíos 
(García y Rodrigo, 2008, pp. 205-209). Surgen así nuevas aproximaciones teóricas, como la seguridad humana y las comunidades de seguridad. La primera responde a las nuevas situaciones de inseguridad propias del fin de la Guerra Fría, expresadas en las denominadas "nuevas guerras" y en la pobreza y el subdesarrollo como causas de este fenómeno. Estas nuevas amenazas serían las pandemias, las crisis económicas, el deterioro ambiental, y desastres naturales, que logran centrar su foco en la inseguridad de los individuos pertenecientes a toda sociedad nacional. En cuanto a la creación de comunidades de seguridad, estas nuevas amenazas supondrían, además, nuevos mecanismos institucionales para afrontarlas. Nos referimos al rol de la comunidad internacional comprometida e interpelada por las nuevas normas constitutivas, como el principio de responsabilidad de proteger, la creación de una identidad colectiva inspirada en la protección de las personas y en la solución pacífica de las controversias con todo lo que conlleva la creación de regímenes internacionales específicos, en tanto que se constituyen en factores o mecanismos de socialización de ideas (Wendt, 2005; Hopf, 1999)

Con todo, conjeturamos que pese a estos cambios del sistema internacional y a estos nuevos enfoques que dan cuenta de ellos, todavía persiste una influencia del realismo en los estudios de seguridad, sobre todo promovidos desde ciertas comunidades epistémicas vinculadas al campo de la defensa. Esta influencia realista puede interpretarse, desde la perspectiva de la securitización (Buzan y Weaver, 1995; Tickner, 2008; Orozco, 2006, 2009), a partir de las nuevas amenazas construidas por los gobiernos latinoamericanos, ya que hoy en América Latina, en el ámbito de la definición de amenazas, predomina el instinto de preservación del gobierno por encima de la defensa de los intereses de seguridad de la sociedad (Tickner, 2008:8). Podríamos agregar también que en sociedades como las conosureñas, donde priman fronteras en transición ${ }^{1}$ (Eskelinen, 2011), también se privilegia ocasionalmente cierto instinto que evoca la integridad territorial y la superioridad vecinal. Éstos se expresan en medidas tendientes a securitizar la agenda pública fronteriza implementada por parte de autoridades del ejecutivo sin mediar -algunas veces- la debida deliberación política democrática que requieren decisiones complejas, como son las enmarcadas dentro de relaciones vecinales².

1. Fronteras en transición hace referencia a los casos donde se han experimentado procesos de largo repliegue e incipiente apertura, sobre todo a procesos que han tenido consecuencias estructurales: los efectos de guerras fronterizas, presencia de doctrinas militares con aprehensiones hacia las zonas contiguas, presencia de regimenes militares que apelan al nacionalismo, etc. Uno de sus principales efectos se denomina territorialización dura; esta apunta a la existencia de controles fronterizos, límites jurisdiccionales, y un interés por la integridad territorial y los derechos soberanos de manera que la división entre actores que están dentro y fuera de la comunidad ("nosotros" y "ellos") están en principio bien definidos (Bialasiewicz, 2005, citado en Eskelinen, 2011, p. 125)

2. En efecto, en el año 2010 en Chile los Ministerios de Defensa e Interior crearon el Plan Frontera Norte. Este busca fortalecer el combate fronterizo al narcotráfico en las regiones de Arica y Parinacota, Tarapacá y Antofagasta. Si bien no contempla ninguna medida legalmente amparada que afecte el flujo migratorio, en la práctica se han implementado medidas, informalmente, que afectan su desarrollo. Es el caso de la decisión por parte de la Gobernación Provincial de Iquique de retener buses para realizar controles de identidad, en sectores no previstos por la legislación vigente, en concreto fuera de los controles fronterizos. Se consideró por algunos sectores de la opinión pública como una 
El objetivo de esta contribución es interpretar el desarrollo y los cambios de algunas de las teorías de las Relaciones Internacionales sobre materias de seguridad presentes en el Cono Sur de Sudamérica ${ }^{3}$, particularmente la discusión que se da en Chile entre las décadas de 1970 y la primera década del siglo XXI. Desde una perspectiva constructivista, indagaremos sobre la evolución de estas teorías a partir de la relación entre agencia y estructura, y particularmente la relación entre distintas comunidades epistémicas de la subregión y los cambios de la estructura internacional subregional en el ámbito de la seguridad y su constitución mutua (Wendt, 2005).

En el primer apartado abordaremos las perspectivas de seguridad realistas en que se inscribe la doctrina de Seguridad Nacional. A continuación discutiremos los aportes del constructivismo, particularmente los referidos a la construcción de comunidades de seguridad y algunos elementos referidos a la Seguridad Humana. Finalmente problematizaremos la influencia de estas últimas a partir de la discusión referida a la securitización de la seguridad en el Cono Sur y plantearemos los aportes de algunas comunidades epistémicas que recogen el debate entre corrientes racionalistas y reflectivistas moderadas.

\section{LAS POLÍTICAS EXTERIORES EN EL ÁMBITO DE LA SEGURIDAD EN EL CONO SUR DESDE EL REALISMO}

\subsection{SURGIMIENTO Y EVOLUCIÓN DE LA DOCTRINA DE LA SEGURIDAD NACIONAL}

América Latina en el periodo de la Guerra Fría se vio sumida en un proceso político guiado por las ideas antagónicas que dieron sentido al mundo en el desarrollo de esta confrontación ideológica (Laïdi, 1997), afectando a sus procesos de modernización y desarrollo, junto a su proyección en materia de política exterior. Por ello surgen estrategias antagónicas, unas de corte dependentistas, y otras, sobre todo en el Cono Sur, que se pueden denominar como antecedentes a la doctrina de la Seguridad Nacional, desarrolladas en el tránsito de la primera a la segunda etapa de la confrontación Este Oeste 4 . En lo referido a la doctrina de la Seguridad Nacional, la

medida arbitraria e inconstitucional, pues afectaba el libre tránsito. En efecto el "Diario el 21" (marzo 28, 2011, 18:37) señala: "En medio de la polémica por la idea de introducir un decreto, por parte de la Subsecretaría de Transportes y Telecomunicaciones -para restringir el ingreso de vehículos de transporte internacional de Bolivia entre la medianoche y las ocho de la mañana, así como la incorporación de una segunda fiscalización para éstos en Huara-, el gobernador de Iquique, Felipe Rojas, volvió ayer a salir a la palestra para aclarar y rectificar el "ruido" que ocasionó la propuesta en la opinión pública y parlamentarios".

3. Pope Atkins (1991:54) señala que América del Sur constituye una entidad coherente, denominada Cono Sur de Sudamérica, subsistema internacional que incluye a Argentina, Brasil, Chile, Uruguay, Paraguay, Bolivia, Perú y Ecuador. El Cono Sur constituye un subsistema regional que se distingue por una serie de patrones visibles. Se trata de valores e intereses comunes, y una posición económica relativamente común hacia el mercado mundial que define interacciones entre sus estados con cierta regularidad.

4. De la etapa de la contención de 1950 a la de la intervención en 1960, cuando se comienza a elucubrar la idea de Guerra total contra el marxismo y que fundamentó la creación de la Escuela de las Américas. 
Alianza para el Progreso se constituye en un claro ejemplo. Este proyecto norteamericano creado en 1961 en el seno del en la reunión del Consejo Interamericano Económico y Social (CIES), surge para frenar la influencia soviética en América Latina a través de estrategias de poder blando, tales como la cooperación económica, técnica y financiera.

En contrapartida, a mediados de la década del 70, surge una respuesta violenta a los proyectos de desarrollo de izquierda inspirados en el dependentismo, pues ésta se trataba de una aproximación estrechamente asociada a procesos de cambio estructural en torno a la modernización de las estructuras productivas, con un fuerte componente de transformaciones políticas revolucionarias (O, Donell, 1972).

En materia de política exterior -fracasada la Alianza para el Progreso en 1970, Estados Unidos se centra en una cooperación bilateral con los países de América Latina en aspectos militares, dando inicio a la doctrina de la seguridad Nacional-, surge, en consecuencia, un realismo latinoamericano con un fuerte énfasis en estrategias de Seguridad Nacional. Para Pope Atkins (1990) su fundamento se encuentra en algunas respuestas nacionalistas al reto modernizador de América Latina, inspiradas en la vigente DSN, de marcado anticomunismo y en doctrinas geopolíticas agresivas. En efecto, según Atkins (1991, p. 471), "se formulan políticas desde un punto de vista de intereses nacionales basados en teorías de seguridad nacional". Ésta se concentra en "los desafíos internos a la unidad nacional, en las percepciones externas limitadas a fronteras contiguas y controversias territoriales" (Atkins, 1991, pp. 471-472). No obstante, por un lado, estas doctrinas agresivas fueron responsables de dar impulso al conflicto en el subsistema del Cono Sur, y, por otro, de justificar la represión interna (Devés, 2003).

\subsection{LOS FUNDAMENTOS REALISTAS DE LA DOCTRINA DE LA SEGURIDAD NACIONAL.}

Desde estos enfoques la seguridad se define desde una visión tradicional estatocéntrica. Para ella la seguridad responde a las amenazas que atenten contra la preservación de la soberanía territorial tanto interna como externa, la primera destinada a erradicar a través de los aparatos del Estado la amenaza comunista, mientras la segunda está asociada a contener y a disuadir a los países vecinos, particularmente con los que se comparte frontera, y con los que se heredaba una rivalidad y percepción de amenaza histórica ${ }^{5}$. En este derrotero, Bolivia, Argentina y Perú se consideraban una amenaza para la seguridad de Chile, reeditando o dando cuenta de patrones culturales de larga duración, que se engarzan con el marco de la compleja historia de la

5. Para el caso de la historia de la estructuración fronteriza de todos los estados Sudamericanos, se dio un proceso a mediados del siglo XIX que definió el contenido de las políticas exteriores de la región: “...la imagen de que en la historia de la estructuración fronteriza del país éste habría sido amputado por un vecino agresivo y expansionista" (Fernandois y León, 2005, p. 96) Para el mismo autor, "cuando en la segunda mitad del siglo XX eclosionaron los problemas limítrofes como la cuestión central en las relaciones bilaterales, se había formado una imagen del vecino ya anclada en una conciencia historiográfica (Fernandois y León, 2005, p. 96)

LA SEGURIDAD INTERNACIONAL EN LA PROYECCIÓN DE CHILE HACIA EL CONO SUR: ¿DESDE LA DOCTRINA DE LA SEGURIDAD NACIONAL HACIA LA CONSTRUCCIÓN DE COMUNIDADES DE SEGURIDAD O LA EMERGENCIA DE LA SECURITIZACIÓN? 
estructuración fronteriza de todos los estados sudamericanos (Fernandois, 2005, pp. 68-83). Esta amenaza se vio reforzada, además, por la llegada de una ideología nacionalista ${ }^{6}$ propia de los regímenes burocráticos autoritarios de América Latina y en particular de Chile, que asociaba al marxismo con valores ajenos a la identidad nacional (Subercaseux, 2006).

Otra de sus prioridades es la inexpugnabilidad de las fronteras territoriales y la integridad del Estado, considerando a este último como un ente monolítico con intereses dados, materiales, vitales y permanentes (Ovando, 2009, p. 41). Interés nacional se considera un concepto inmóvil, una realidad material irreductible al Estado, en este caso a un Estado autoritario con todo lo que conlleva ${ }^{7}$. Para el realismo, la seguridad de las personas está asociada a la del Estado, pues su supervivencia garantiza la posibilidad de que la sociedad pueda desplegarse. Para preservar la seguridad los medios preferentes son el militar: basado en el poder material o poder duro, la disuasión militar del Estado y la represión contra la -denominada por ellos- insurgencia en el ámbito interno (guerra interna contra el marxismo).

Estas amenazas provienen de un sistema internacional descentralizado, anárquico y violento en que cada unidad - egoísta y autointeresada- del sistema resuelve el dilema de la seguridad de manera individual por la vía militar. Pues para el neorrealismo las estructuras internacionales emergen de la coexistencia de los Estados que se despliegan guiados por principios ordenadores, destacando el de auto-ayuda o esfuerzo egoísta para la seguridad ${ }^{8}$ y sobrevivencia (Waltz, 1979 , p. 133). Desde la óptica del neorrealismo, "la necesidad y el deseo de seguridad en un contexto en que se carece de autoridad por sobre los Estados, conduce a éstos a la acumulación del poder" (Herrero, 2010, p. 25).

Por otro lado, constituye un axioma realista que la seguridad nacional se alcanza mediante el equilibrio de poderes ya sea de manera espontánea o premeditada a través de políticas (Sodupe, 2003). En el Cono sur, la percepción de la búsqueda de un equilibrio militar, regional, se constituye como un elemento fundamental de las relaciones vecinales, en la medida que se concebía como clave para la defensa ante la amenaza vecinal (Fernandois y León, 2005). El equilibrio del poder siempre ha estado presente en la política exterior latinoamericana, en vista a un escenario regional multipolar, la falta de sistemas hegemónicos y la presencia de constantes

6. En este mismo sentido el discurso de Pinochet emitido en 1976 es lapidario: "Acta Institucional №2 (1976)....las Fuerzas Armadas y de orden en cumplimiento de su deber esencial de resguardar la soberanía de la Nación y los valores superiores y permanentes de la chilenidad a justo y legítimo requerimiento de aquella, asumieron el 11 de septiembre de 1973, la conducción de la República con el fin de preservar la identidad histórica, cultural de la Patria y de reconstruir su grandeza espiritual y material"(citado en Corlazzoli, 1978, p. 113.Cursivas en original)

7. En efecto, dentro de los intereses permanentes se contemplaba resguardar la chilenidad y vaciar de ella todo contenido foráneo en el ámbito cultural y social (Subercaseux, 2006)

8. Los sistemas políticos internacionales, al igual que los mercados económicos, se forman por la coacción de unidades autointeresadas. Las estructuras emergen de la coexistencia de los estados. Son de origen individualista, espontáneamente generados y no premeditados (Waltz, 1979, pp. 33-135) 
desajustes, que orientaban las políticas a nuevos ajustes de poder (Lacoste, 2005, pp. 93-141). No obstante, si pretendemos explicar con mayor precisión el rol del equilibro en la búsqueda de seguridad, resulta relevante complementarlo con la idea de equilibrio de amenazas. Stephen Walt (1985), complementando la teoría estructural, estudia la formación de alianzas y sus variantes. Plantea que los Estados si bien se preocupan por su propia seguridad, no lo hacen contra el predominio de un poder, pues los atributos de poder son neutros, sino contra el predominio de amenazas para su seguridad. Por ello lo que primaría en el sistema internacional sería el equilibrio de amenazas a través del acercamiento de las unidades políticas más débiles a los respectivos núcleos de poder o bandwagoning.

Así, el comportamiento estatal es una respuesta a las amenazas que provienen de otros Estados y que resultan de una combinación de factores (Walt, 1985, pp. 27-32): 1) acumulación de recursos de poder, en el caso del Cono Sur las carreras armamentistas son recurrentes durante toda la segunda mitad del siglo XX; 2) proximidad geográfica, se trata de países que comparten fronteras y rivalidades fronterizas históricas desde los procesos de independencia (Fernandois, 2004); 3) intenciones agresivas, recurrentes por parte de los tres países durante todo el siglo XX, al punto que Taylor (1987) plantea la persistencia de una "geopolítica agresiva instintiva" en el continente desde la independencia. Además, las percepciones juegan un papel clave en la formación de alianzas, pues si se percibe a un Estado como agresivo, aun cuando no tenga grandes capacidades de poder, este constituye una fuente de amenaza. Esta idea planteada por Jervis, apunta a la obsesión de los Estados por buscar su seguridad en un contexto internacional donde prima la desconfianza, pues la falta de una autoridad supranacional crea percepciones de inseguridad (1976: 64) En efecto, el enfoque de las percepciones -imágenes e ideologías- es considerado una aproximación a tener en cuenta para abordar las relaciones bilaterales de los países sudamericanos, a partir de "la hipótesis según la cual (...) la visión del otro -sustentadas a menudo en imágenes erróneas o preconceptos-, habrían influido en la formulación de las respectivas políticas externas, en particular sobre las relaciones bilaterales limítrofes" (Bernal-Meza, 2005, p. 278).

Con todo, la DSN, en clave neorrealista, constituye una aproximación teórica de gran impacto político en el continente suramericano. Contempla "una concepción social global, pero desde un ángulo eminentemente militar. Además, ha sido la tendencia más destacada para militarizar el concepto de seguridad" (Leal, 1978, p. 7), al punto que su geopolítica agresiva afectó los vínculos entre los países vecinos, desarticulando las históricas relaciones de cooperación transfronteriza emprendidas por regiones y provincias de los países del Cono Sur (Lacoste, 2003).

Desde una perspectiva reflectivista (Der Derian, 1987; Smith, 1995), la vinculación entre anarquía, soberanía, seguridad nacional, con atributos permanentes y dados -en tanto narrativas-, y el orden bipolar de la Guerra Fría, todo ello contribuyó a blindar las Relaciones Internacionales de pensamientos alternativos (Herranz,2009). En efecto, esta corriente crítica fue la primera en problematizar estas categorías negando su carácter de leyes objetivas. Al punto que anarquía, 
soberanía y seguridad nacional "se consideraba[n] como una construcción social, históricamente contingente, y una herramienta al servicio del poder (Herranz, 2009, p. 51).

Estas críticas las retomaremos desde los enfoques reflectivistas -constructivismo y securitización- que a continuación revisaremos.

\section{LOS NUEVOS ENFOQUES DE SEGURIDAD: CONSTRUCTIVISMO, SEGURIDAD HU- MANA, COMUNIDADES DE SEGURIDAD Y SECURITIZACIÓN}

El periodo de pos Guerra Fría coincide con que el Cono sur se encuentra en un proceso de transición a la democracia. Este desafío conlleva que los países del extremo sur de América deben reinsertarse en la región y el mundo en los ámbitos político (por la vía del multilateralismo) y económico, lo que supone que sus políticas giren desde lo defensivo militar a la apertura comercial (Witker, 2000). Se llega al consenso de que la búsqueda de la confianza en el ámbito de la seguridad, sobre todo a partir de la creación de mecanismos institucionales, contribuirá a una concertación política en clave constructivista (González y Ovando, 2009).

Surge así una triada en el continente, que marca la década del 90, entre neoliberalismo, democracia y respeto a los Derechos Humanos (DD.HH). Paralelamente, surge un debate en torno a replantear los conceptos vigentes de seguridad. En respuesta a ello, en las últimas dos décadas (1990 - 2010), los países han ido modificando su política exterior en el ámbito de la seguridad, planteándose estrategias que tomen en cuenta las transformaciones del sistema internacional y del ámbito doméstico en torno a la democratización de los países y la emergencia de nuevos debates teóricos en las Relaciones Internacionales (RR.II.) en torno a la seguridad cooperativa y la seguridad humana.

Pese a que los intereses nacionales de los Estados siguen centrándose en su supervivencia, el bienestar económico y la búsqueda de autonomía, ahora se concretan y deliberan de manera concertada o relacional y no de forma aislada (Russell y Tokatlián, 2000). Puesto que, según Wendt (2005), si bien estos intereses predisponen a los Estados a actuar de cierta manera, su contenido y relevancia dependen del contexto político y cultural dentro del que se formula la política exterior, pudiendo verse modificado por ellos en contextos de distensión y mayor concertación política, como es el caso del Cono Sur en los 90.

\subsection{LOS APORTES CONSTRUCTIVISTAS AL REPLANTEAMIENTO DE LA NOCIÓN DE SE- GURIDAD.}

Siguiendo con esta perspectiva constructivista, Witker (2000, p. 127) señala que para el Cono Sur se plantea el surgimiento de una lectura renovada del término interés nacional. Esta sostiene que "...en democracia, (...) podría ser un conjunto de prioridades compartidas con el resto del 
mundo, dentro de los que cabrían los Derechos Humanos y los valores democráticos, siempre y cuando la opinión pública se sienta identificada con ellos".

La aportación del constructivismo al concepto se relaciona con salir de denominaciones inmóviles. Así, los conceptos dejan de ser realidades materiales para convertirse en construcciones sociales (Wendt, 2005). Pues la realidad, en vez de estar "allí", es producto de un conjunto de prácticas sociales y políticas que constituyen el mundo (Campbell, 1992, p. 4, citado en Tickner, 2008, p. 6).

Para los constructivistas, "el interés nacional es el resultado de ideas compartidas, identidad nacional y prácticas normativas" (Herrero, 2010, p. 28). Para este mismo autor: "Lejos por tanto de ser un concepto estático, los intereses nacionales de los estados se forman dentro de un contexto cultural como resultado de la interacción social" (Herrero, 2010, p. 28).

Por tanto, la seguridad, al igual que el interés nacional en tanto construcciones sociales, ya sea nacional, cooperativa, humana o colectiva, surge de la socialización y el aprendizaje mutuo; por ello se construyen realidades y contenidos respecto a la seguridad desde un "concepto intersubjetivo del proceso en el que las identidades y los intereses son endógenos a la interacción, en lugar de ser exógenos y dados, como apunta el concepto racionalista representado por las variantes realistas" (Hopf, 1998, p. 199). Como afirma Ted Hopf (1998, p. 200), "Mientras que el constructivismo trata a la identidad como una cuestión empírica a ser teorizada dentro de un contexto histórico, el neorrealismo asume que todas las unidades de la política global tienen solamente una identidad relevante, la de estados auto-interesados". Con ello esa identidad define la seguridad de manera invariable según los contenidos de esa identidad autointeresada: seguridad como dilema individual, abordado por cada Estado desde políticas militares. Contrariamente, para constructivistas el contenido de los intereses y la seguridad cambian según interactúen agente y estructura en un contexto determinado moldeándose mutuamente y reconfigurando sus identidades, pasando de una seguridad nacional a una cooperativa según como operen o no desde identidades egoístas a identidades colectivas.

Con todo, el constructivismo constituye una aproximación renovada de los estudios de seguridad, sobre todo a partir del argumento que señala que las instituciones de seguridad o el conjunto de estructuras e identidades en torno a la seguridad difieren en función de cómo el yo se identifique cognitivamente con el otro (Wendt, 2005, p. 9). Niegan la existencia de una definición universal de seguridad o de fuente de una amenaza (Mac Donald, 2008). Cuando plantean, por ejemplo, estrategias de seguridad nacional, esta se define por los sentidos que le dan los agentes, así los líderes de Estado designan a otros Estados como amigos o enemigos y se aproximan a ellos como tales en base a sus concepciones de identidad y al cotejar sus valores (Mac Donald, 2008, p. 60). La definición constructivista de seguridad profundiza en cuáles son esos valores, de dónde pueden venir amenazas a esos valores y de cómo la preservación de esos valores podría conseguirse (Mac Donald, 2008, p. 60). En efecto, en el caso de la seguridad 
humana, esos nuevos valores provienen del contexto cultural de su surgimiento, contexto marcado por la valoración de los individuos en desmedro del Estado, el auge de la tercera ola democratizadora, el surgimiento de amenazas globales, el nuevo orden y la distensión, el colapso de Estados en varias zonas, entre otros. El origen de la seguridad humana, en concreto, se encuentra en el informe del PNUD de 1994 en respuesta al creciente subdesarrollo y empobrecimiento del Sur tras la década perdida. Éste enfoque reorienta la seguridad a partir de valores como "universalidad", pues las amenazas son comunes a la humanidad, y que esté centrada en los seres humanos como objetos referentes de la seguridad (García y Rodrigo, 2008, p. 208). Según el PNUD, siete son los valores de la seguridad humana que deben ser protegidos: seguridad económica, alimentaria, de salud, del medio ambiente, personal, comunitaria y política (García y Rodrigo, 2008, p. 208). En síntesis, cambian los valores a proteger (ya no es prioridad la integridad territorial de los realistas), los mecanismos para garantizarla (ya no pasan por la acción aislada de cada Estado en clave militar) y los actores encargados de velar por ella (se da prioridad a la comunidad internacional en desmedro del Estado). Esta interpelación llega a tal punto que obliga teóricamente al Estado a responsabilizarse por la seguridad de sus ciudadanos, redefiniendo principios fundamentales de la columna vertebral del sistema internacional, como el de soberanía por el de responsabilidad de proteger (García y Rodrigo, 2008, pp. 208-223).

En efecto, para el constructivismo es clave el rol de las normas, sobre todo las constitutivas, que pueden ser definidas como expectativas compartidas por actores, con una particular identidad, acerca de su comportamiento apropiado o legítimo. Esto se aplica a ideas dominantes acerca de qué constituye el comportamiento legítimo para los Estados de una sociedad internacional (MC Donald, 2008, p. 60). Para esta, un Estado canalla, paria o fallido sería una amenaza a la seguridad regional y global, pues vulnera las expectativas de comportamiento legítimas - por ejemplo al no respetar la responsabilidad de proteger, los principios democráticos, el derecho internacional humanitario, etc. -, según cómo se ha ido construyendo la identidad colectiva en seguridad, pues atenta contra valores institucionalizados en normas constitutivas.

Otra dimensión apunta a que los constructivistas enfatizan el hecho de que la seguridad es un espacio para la negociación entre líderes y ciudadanos en particular, y de interpelación entre diferentes actores que elaboran diferentes visiones respecto a "nuestros valores y de cómo nosotros deberíamos actuar" (Mac Donld, 2008, p. 60). Esto es importante a la hora de definir las políticas públicas de seguridad, en la medida que la opinión pública juzga la legitimidad de la autoridad de turno al escrutar los contenidos de dichas políticas. En efecto, la opinión pública está en una posición relativamente fuerte para incidir en los discursos de política exterior de seguridad, lo que ocurriría mediante la intervención de varios actores no estatales en la alteración del contexto normativo en el que las élites políticas operan (Mac Donald, 2008, p. 62). En torno a la seguridad humana surge un debate acerca de cuáles valores deberían ser objeto específico de atención con relación a la garantía de la seguridad, pues su extensión a temas diversos y complejos conllevaría una serie de problemas. Este debate se divide entre los que apuntan solo a las situaciones de violencia o temor (derechos políticos y civiles) y los que la 
extienden al bienestar (derechos sociales y económicos). Esto conllevó la dificultad de concretar políticas de seguridad hacia temas tan amplios, propios de la agenda extensiva (García y Fernando, 2008, p. 8).

\subsection{LOS APORTES DE LAS COMUNIDADES DE SEGURIDAD}

Otros constructivistas, como Adler y Barnett (1998), se centran en la posibilidad de abordar el dilema de seguridad humana a través de la construcción de comunidades de seguridad y su definición a partir de significados colectivos. Se trata de grupos de Estados, para quienes el uso de la fuerza en la resolución de disputas se ha convertido en algo impensable. Privilegian la cooperación en materia de seguridad y la posibilidad de construir alternativas de seguridad a través de la institucionalización de normas compartidas en torno al bienestar de los individuos que conforman dichas comunidades.

Este enfoque está basado en el reconocimiento de que la definición de seguridad desde cada unidad de manera excluyente y la asunción de mutua desconfianza entre Estados no es una característica inevitable de la política mundial producida por la anarquía. Más bien, debería ser visto como una construcción social específica de momentos históricos y formas de identidad política particulares que responden a procesos en que el cambio de la estructura de seguridad es posible (Adler y Barnett, 1998, p. 30). En efecto, la seguridad nacional corresponde a un momento histórico particular -Guerra Fría- y a formas de identidad política antagónicas en que primaba la hostilidad hacia los países vecinos o, como señala Taylor (1987), persistía una "geopolítica agresiva instintiva" en el continente.

Adler y Barnett (1998, p. 30-32), señalan que una comunidad de seguridad pluralista es una región transnacional de Estados soberanos cuyos pueblos tienen razonables expectativas hacia el cambio pacífico. Los miembros de comunidades de seguridad enlazadas esperan que otros miembros se comporten en forma no belicosa y, por lo tanto, también se auto-restringen. En ella los Estados comparten identidades, valores y significados, y existe una reciprocidad que expresa intereses a largo plazo y sus miembros albergan expectativas fiables de un cambio pacífico.

Cuanto mayor es la cohesión de esta comunidad, "más se transformará el rol limitado del Estado hacia una comunidad civil transnacional, expandiendo este papel para cumplir con las demandas de mayor seguridad, bienestar económico, derechos humanos, un medio ambiente limpio, etc., de la comunidad" (Adler y Barnett, 1998, p. 36).

En la formación de las comunidades de seguridad se plantean tres fases propicias para su formación. En la primera (Adler y Barnett, 1998, pp. 37-38) se trata de factores internos y externos (nivel de desarrollo, nueva realidad social, transformaciones económicas, etc.) que acercan a los 
estados a colaborar en ciertos aspectos que les permiten alcanzar objetivos superiores. En una segunda fase, se toman en cuenta las relaciones recíprocas entre la estructura de la región y los procesos sociales (Adler y Barnett, 1998, p. 39), y los Estados y sus pueblos se han involucrado en una serie de interacciones sociales que han comenzado a transformar el entorno en el que están inmersos. Se plantean factores que propician el desarrollo de una confianza mutua y una identidad colectiva. Por otro lado, un crecimiento cualitativo y cuantitativo de las transacciones modela la experiencia colectiva y altera los hechos sociales modificando la estructura, pues las organizaciones e instituciones internacionales promueven la confianza mutua, la identidad compartida. Todas las organizaciones contribuyen al desarrollo de la confianza estableciendo normas de comportamiento, mecanismos de control y sanciones.

\section{3. ¿HACIA COMUNIDADES DE SEGURIDAD EN EL CONO SUR?}

La redemocratización del continente conllevó la creación y el relanzamiento de bloques regionales como el MERCOSUR y la Comunidad Andina. Entendidas como comunidades de seguridad, fueron posibles por una serie de procesos. Dentro de ellos destacamos: la democratización de los países de la región, la concertación de estrategias económicas liberales y la proliferación de procesos de cooperación y coordinación de políticas que se desarrollan por ellos, la mayor autonomía hacia Estados Unidos en temas de seguridad al crearse UNASUR y el Consejo Sudamericano de Defensa ${ }^{9}$ (Álvarez y Ovando, 2009, pp. 552-554). Surge así en el marco de las políticas de seguridad -recogiendo el debate desarrollado hasta ahora-, la implementación de una agenda clave en torno a la publicación de "libros blanco de defensa", homologación de gastos militares y emprendimiento de operaciones de paz multinacionales e intervenciones humanitarias orientadas por el principio de responsabilidad de proteger, entre otras. Estas iniciativas son fundamentales para poder establecer regímenes internacionales más o menos institucionalizados, de los que se posibilite concebir una identidad colectiva que ampare acuerdos ambiciosos en materia de seguridad cooperativa para América del Sur (Flemes, 2003; Álvarez y Ovando, 2009).

En el área específica de la seguridad se puede comprobar la creación de nuevas normas constitutivas. En la Organización de Estados Americanos (OEA) se crea la Declaración sobre Seguridad

9. En el ámbito de la seguridad, los Estados Unidos históricamente han influido en las políticas regionales, dificultando la construcción de instancias de seguridad con mayores niveles de autonomía (Buzan y Waever, 2003), condicionando los valores e intereses compartidos o contrapuestos que se vislumbren entre los estados vinculados por procesos de integración latinoamericano.

10. Una serie de tratados a nivel regional y subregional se han suscrito en el continente, de los cuales la OEA es depositaria. Entre ellos destacan: Declaración de Brasilia sobre el Comercio llícito de Armas Pequeñas y Armas Ligeras (2000); la Declaración Presidencial conjunta entre Argentina y Chile sobre Fomento de la Confianza y Seguridad (1999); Declaración Política del MERCOSUR, Bolivia y Chile como Zona de Paz (1999); Declaración de Salta, 1996 y El Protocolo de Ushuaia sobre Compromiso Democrático en el MERCOSUR (Ushuaia, 24 de Julio de 
de las Américas (2003) o la Carta Democrática Interamericana (2001), se ha redefinido el rol de la Junta Interamericana de Defensa (JID), y en términos generales se ha promovido el diálogo y la concertación hemisférica en materias de seguridad desde una perspectiva democrática ${ }^{10}$ (Álvarez y Ovando, 2009, p. 558). Adicionalmente, destacan las reuniones bianuales de Ministros de Defensa de las Américas, lugar de encuentro para la discusión de posiciones y búsqueda de miradas compartidas acerca de la seguridad regional; o la misión de paz desplegada en Haití (MINUSTAH), integrada por efectivos en su mayoría latinoamericanos. También la existencia de diversos acuerdos en el nivel bilateral, siendo un ejemplo paradigmático el Comité Permanente de Seguridad (COMPERSEG) entre Argentina y Chile, que ha llevado a una avanzada relación de cooperación entre ambos países ${ }^{11}$ (Álvarez y Ovando, 2009, p. 558).

En síntesis, las políticas exteriores hacia la seguridad desde los 90 se dan al amparo de normas constitutivas novedosas, que aportan hacia la construcción de significados compartidos; como hemos señalado, en el marco de intereses nacionales definidos internacionalmente (Witker, 2000), que surgen de la socialización de ideas y prácticas en el seno de aquellas. Se destacan principios orientadores, entre los cuales la paz, la democracia, el respeto a los derechos humanos, la concertación regional desempeñan un rol clave. De ellos "se desprenden mecanismos operativos que contribuyen al diseño y establecimiento de potenciales regímenes internacionales específicos" (Álvarez y Ovando, 2009, p. 559).

No obstante, podemos señalar que los países del Cono Sur, en tanto miembros que componen UNASUR, "pretenden establecer una comunidad de seguridad rigurosa, pero aún se encuentra en la etapa ascendente de su evolución" (Flemes, et. al., 2011, pp. 107-108). Es decir, quienes intentan conformarla todavía deliberan, sin resultados verificables, respecto a los factores internos y externos (nivel de desarrollo, nueva realidad social, transformaciones económicas, etc.) que los acerquen para colaborar en ciertos aspectos que les permitan alcanzar objetivos superiores. Y se encontraría a medio camino, además, el vínculo entre la estructura de la subregión cono sureña y los procesos sociales de los Estados involucrados, que les permitan transformar el entorno en el que están inmersos (Adler y Barnett, 1998).

1998), fue firmado por los cuatro Estados Partes del MERCOSUR, junto con Chile y Bolivia. Creación del Mecanismo de Consulta y Concertación Política, en el que se consensuan posiciones comunes en materias de alcance regional. Suscripción de la Declaración Política del MERCOSUR, Bolivia y Chile como zona de Paz (www.mercosur.org).

11. Ejercicios conjuntos entre los ejércitos de Bolivia, Chile y Argentina, que han decidido integrar mandos de manera alternada en algunas operaciones de paz, así como desarrollar un fluido intercambio para la capacitación de su personal en esas actividades. Acercamiento entre FF.AA de Chile y Bolivia, con sucesivas visitas y programas de cooperación a partir de la llegada a los Gobiernos de los Presidentes Evo Morales, en Bolivia, y Michelle Bachelet, en Chile. Se han realizado una serie de reuniones bilaterales con miras a transparentar sus gastos y los dispositivos de defensa con que cuenta. Chile presentó dos Libros de la Defensa; el primero, en 1997, y el segundo en el 2003. Por su parte, Bolivia lo hizo en el 2004. 


\section{LA SECURITIZACIÓN DE LAS POLÍTICAS EXTERIORES EN MATERIA DE SEGURIDAD}

Pese a este panorama optimista marcado por el avance internacional en el ámbito de institucionalización de la seguridad cooperativa, una dificultad importante que enfrenta América Latina para consolidar opciones cooperativas de seguridad es la securitización de los problemas domésticos (Orozco, 2006; Dammert y Bailey, 2005).

\subsection{EL ENFOQUE DE LA SECURITIZACIÓN, ALGUNOS ASPECTOS CLAVE}

Desde una perspectiva reflectivista, los autores de la Escuela de Copenhague han argumentado que las nociones de seguridad, inseguridad y amenaza, como todo concepto, implican un uso político como discurso, construido por los actores estatales y respondiendo a sus intereses puntuales, que se manifiestan en la identificación de ciertos temas objeto de seguridad (Weaver,1995). Los discursos emanados de la autoridad, por tanto, conllevan ideas de seguridad particulares a cada grupo que tiene una posición privilegiada en las relaciones de poder: "éstos no son el producto de evaluaciones objetivas ni de constructos analíticos sobre las amenazas a la seguridad sino que son consecuencia de estructuras y procesos históricos, de la lucha por el poder y del conflicto social" (Lipschutz, 1995, p. 8, citado en Tickner, 2008, p. 5). En consecuencia, debemos apuntar a un análisis que enfatice en el "por qué y cómo las elites políticas identifican ciertos problemas como amenazas a la seguridad" (Waever 1995, p. 49, citado en Tickner, 2008 , p. 2). En el mismo sentido Mc Donalds (2008, p. 62) señala que diferentes actores se comportan de acuerdo a diferentes discursos o marcos de significado de seguridad. Así abordado el problema de seguridad, son las elites políticas las que tienen la posibilidad de hegemonizar el sentido que se le atribuye a la seguridad en un momento dado.

Por otro lado, Barry Buzan (1991) plantea que es necesario tener en cuenta la multiplicidad de objetos referentes de la seguridad, esto es, la seguridad se puede referir unas veces al Estado, otras al sistema internacional y en algunos casos al individuo concreto y es por ello mismo que la seguridad tiene varios sectores en los que se despliega de manera paralela y simultánea. En este sentido, el manejo del lenguaje en torno al contenido que define la seguridad busca doblegar una determinada concepción de la sociedad con efectos hacia la seguridad y así imponer el propio detrimento del bienestar de la sociedad. Es aquí en donde surge el término de Securitización (Orozco, 2006, p. 144-145; 2009).

\subsection{APLICACIONES DEL ENFOQUE DE LA SECURITIZACIÓN EN EL CONO SUR}

Dada la capacidad de movilizar recursos simbólicos y materiales que tienen los Estados, para buscar la legitimidad de los ciudadanos, los sentidos que le atribuyen a la seguridad es un proceso complejo, pues pueden manipular a la opinión pública securitizando ciertos temas de la agenda internacional (Orozco, 2006, p. 144-145). Por ejemplo, referido al Cono Sur, encontramos las rivalidades fronterizas históricas (Fernandois, 2004), muchas veces ya zanjadas. 
Con ello, lo que buscan las elites de turno es construir una amenaza vecinal que en muchas ocasiones -en el caso del Cono Sur-, productos de la distensión y el cambio de la agenda regional desde los 90, ya no la constituyen de manera verificable (Ovando, 2008, pp. 236-238). En efecto, Fuentes (2008) señala que estas amenazas pueden surgir por dos vías, la persistencia de la geopolítica tradicional en las percepciones de las elites o, deliberadamente, por su instrumentalización. Un ejemplo ilustrativo se refiere a la instrumentalización de los litigios internacionales pendientes como estrategia de política exterior con miras a buscar réditos en el ámbito domestico con la opinión pública según las preferencias y orientaciones (en ocasiones apelando a una retórica nacionalista) del gobierno de turno, sobre todo en momentos en que se ve mermada su popularidad o cuando sufren crisis de gobernabilidad ${ }^{12}$.

En efecto, si bien la persistencia de definiciones geopolíticas tradicionales genera relaciones competitivas en la subregión, sobre todo en la dimensión fronteriza de éstas (Ovando y Álvarez, 2011, pp. 78-79), esta razón no sería suficiente, pues en varios casos se han modificado estos patrones realistas; de ahí que "muchas veces esta lógica competitiva sea producto de las dinámicas internas, derivadas, por ejemplo, de la revitalización de nacionalismos, particularmente cuando los gobiernos tienen bajos niveles de popularidad" (Fuentes, 2008, pp. 3-4).

Esta instrumentalización también responde en ocasiones a las respuestas a la ampliación de las amenazas propias de la noción de seguridad humana extendida y a la incapacidad de los Estados de la región para hacerle frente de manera adecuada y sin recurrir a la coacción. Es el caso de la erradicación del tráfico de drogas y la violencia urbana, el control de la migración compulsiva, la degradación del medio ambiente, la crisis económica, entre otras nuevas amenazas que ponen acento en la seguridad del individuo o la seguridad humana (García y Rodrigo, 2008). Por tanto, el problema en torno a la instrumentalización de las amenazas radica en "decidir que todo problema de seguridad conlleva el riesgo de "seguritizar" su respuesta a través del uso de la fuerza pública o fuerza militar, sin considerar la esencia o naturaleza del problema a enfrentar" (Griffiths, 2008, p. 20). Para Hurrel (1998), este argumento se ve reforzado debido a la debilidad del Estado latinoamericano, quien no garantiza las condiciones de seguridad dentro de las fronteras nacionales. Esto dificultaría, además, la proyección hacia comunidades de seguridad duraderas.

Los riesgos de securitización en América Latina también se refuerzan debido a que los enfoques de seguridad nacional han estado tradicionalmente centrados en temas militares; en

12. Leyton (2005, p. 10) destaca diversos ejemplos tanto contemporáneos como a lo largo del siglo XX: “uno de los más emblemáticos estará dado por la crisis del Canal Beagle con Argentina entre 1977 y 1980, problemática (territorial) "instrumentalizada" por el gobierno militar transandino (...). Ejemplos más recientes en que podemos observar cómo la percepción chilena en torno a la instrumentalización que los gobiernos peruanos y bolivianos han realizado en orden a estabilizar y afianzar un apoyo político/electoral extrema-damente débil en sus respectivos países sirviéndose para ello de problemáticas (territoriales), que para el gobierno de Chile son inexistentes". Dentro de ellos podemos destacar el intento boliviano por multilateralizar la demanda marítima y su estrategia, siguiendo al Perú, de llevar litigio al Tribunal Internacional de la Haya (2012). 
este sentido se les atribuye a las fuerzas armadas la capacidad para afrontar las nuevas amenazas en contextos de estados desbordados, puesto que en el continente los militares han jugado un papel histórico importante en la imposición del orden interno y garantes del orden (Álvarez y Ovando, 2009, p. 555).

Con todo, la debilidad del Estado, conlleva, entre otras consecuencias, soluciones contingentes en clave securitización, el desvío de los problemas internos hacia disputas externas, y en definitiva, limitan las posibilidades de llevar a cabo una política exterior coherente y sostenible en el tiempo, tendiente hacia una mayor concertación regional hacia una seguridad colectiva (Álvarez y Ovando, 2009, pp. 555-556).

\section{ALGUNAS COMUNIDADES EPISTÉMICAS EN TORNO A LAS DEFINICIONES DE SE- GURIDAD}

Vistos algunos aspectos de la evolución de las aproximaciones teóricas respecto a la seguridad presente en el Cono Sur, a continuación abordaremos algunas de las teorías que privilegian las comunidades epistémicas ubicadas en esta subregión, particularmente las chilenas. Previamente describiremos de manera breve esta categoría.

Desde una perspectiva constructivista, señalamos que la evolución de las teorías analizadas se centra en la producción de conocimiento derivado de la interrelación entre agencia y estructura, y particularmente de la relación entre distintas comunidades epistémicas de la subregión y los cambios de la estructura internacional subregional en el ámbito de la seguridad y su constitución mutua (Wendt, 2005). Siguiendo esta teorización, el concepto de comunidad epistémica en las relaciones internacionales, según la definición de Peter Haas, se concibe como agrupaciones creadoras de creencias intersubjetivas que actúan como "vehículos de supuestos teóricos, interpretaciones y significados colectivos que pueden ayudar a crear la realidad social de las relaciones internacionales" (Salomón, 2002, p. 36). En este marco se inscriben distintas entidades productoras de conocimiento respecto del campo de la seguridad. Éstas promueven una determinada visión de la misma y de sus amenazas, incidiendo en la construcción de la realidad subregional en el campo de la seguridad, según sus valores e intereses, de manera más o menos satisfactoria mediante la orientación de estrategias de política exterior para garantizar dicha seguridad.

Se trata, desde esta perspectiva de análisis, de unas acepciones de seguridad y amenazas consideradas como una construcción social, históricamente contingente, emanadas desde estas comunidades. Además, las comunidades epistémicas, en tanto en cuanto agrupaciones, promueven una seguridad centrada en el Estado, en las amenazas globales, en el individuo y/ o la comunidad subregional. Por tanto, recogen las tres teorías revisadas: las realistas, las constructivistas y las referidas a la seguridad humana. 
En cuanto al puente entre producción de conocimiento sobre seguridad y política exterior, para Peters (2003, p. 195), "estas comunidades son conceptualizadas como acuerdos sobre determinados cuerpos de conocimiento que pueden entonces funcionar como un mecanismo para imponer estas opiniones profesionales y científicas al gobierno", quien define las prioridades de política exterior y defensa en torno a la seguridad teniendo en cuenta estas definiciones. Además, continúa Peters, respecto a cómo operan las comunidades epistémicas (2003, p. 195), "existe un acuerdo entre países de manera que haya reacciones relativamente uniformes de los gobiernos nacionales. Esa reacción uniforme depende en parte, no obstante, de la habilidad de los científicos y otros profesionales de influir sobre sus gobiernos nacionales". Esta afirmación es relevante pues pone en debate la constricción e influencia de las denominadas comunidades de seguridad y su influencia en la definición del contenido concertado por los países de la región en el ámbito de la seguridad y amenazas, determinando ciertas prioridades y no otras, prioridades enfatizadas por las respectivas comunidades epistémicas.

Dentro de las comunidades epistémicas chilenas referidas a temas de seguridad destacamos centros de estudios vinculados sobre todo a las Fuerzas Armadas y al Ministerio de Defensa. También son los casos del CESIM, creado en 1994, Centro de Estudios e Investigaciones Militares, dependiente del Ejercito de Chile y ANEPE, Academia Nacional de Estudios Políticos y Estratégicos, dependiente del Ministerio de Defensa. Ambos, en cuanto a escenarios de seguridad vecinal y regional producen conocimiento desde una óptica preferentemente realista, aunque no exclusivamente. Dentro de ellos destacamos los trabajos de Salgado e Izurieta (1992) y Leyton (2007). Los primeros analizan las relaciones peruano- chilenas. Éstas, según su propuesta, estarían marcadas por una conflictividad recurrente resultante de factores materiales, sobre todo territoriales que edificarían intereses nacionales antagónicos. El segundo, desde la perspectiva de las percepciones de amenaza peruana, se adentra en su génesis y prospectiva. Plantea que la animosidad hacia Chile contiene hitos y factores subjetivos que han contribuido a explicar su arraigo de carácter cíclico y permanente entre ambos países, lo que denomina rivalidad histórica duradera, marcada por la Guerra del Pacífico y sus efectos en la identidad peruana y en la pugna por la influencia geopolítica hacia el pacífico entre ambos países. Destacamos, también en clave realista, la emergencia de nuevas amenazas potenciales al Estado provenientes de reivindicaciones indígenas (Zepeda, 1996). Por su parte Witker (2010) planea las dificultades propias de la dinámica integracionista latinoamericana producto de la preeminencia de conductas guiadas por el balance por miedo o por amenaza -bandwagoning- . En concreto Brasil y Venezuela, en tanto países núcleo de la región, han ensayado estrategias para conseguir alineamientos y producir bandwagoning en el espacio subregional. Por otro lado, Griffiths (2008) plantea los riesgos de ampliar o estirar el concepto de seguridad en América Latina y así evitar el riesgo de securitizar el escenario político hemisférico; plantea los riesgos de un concepto extensivo de seguridad humana en contextos de estados latinoamericanos con problemas de gobernabilidad.

Por otro lado, en el Programa Fuerzas Armadas y Sociedad de FLACSO, Chile es un referente importante en lo referido a discusión académica sobre seguridad. Este centro de investigación 
privilegia trabajos en torno a corrientes reflectivistas moderadas como es el caso de trabajos vinculados a la securitización y la formación Comunidades de Seguridad en América Latina. En concreto da prioridad a trabajos relacionados a las posibilidades de orientar el derrotero del continente, desde los procesos de democratización, a partir de las década de los 90, por la vía de la seguridad cooperartiva y la multilateralización de la misma. Destacamos también los trabajos de Rojas Aravena (2000, 2002), Forsberg (1995), Nogues (1998), Michelena, López (2000), Carrión (1998), Flennes (2003), Kurtenbach (2001). En cuanto a los peligros de la securitización y la militarización de la seguridad en la región en contextos democráticos desatacamos los trabajos de Orozco (2006) y Dammert y Bailey (2005). Este centro además tuvo una importante influencia en la política exterior y de defensa de los gobiernos de la Concertación de Partidos por la democracia de Chile (1990-2009), evidenciada en los trabajos publicados por ministros de defensa de los respectivos gobiernos y otras autoridades vinculadas al área seguridad y defensa, sobre todo en lo referido a libros blancos de defensa, homologación de gastos militares, perspectivas de seguridad regional, entre otras materias.

Con todo, estos agentes promotores de una visión u otra de seguridad contribuyen a crear la realidad social que supone las relaciones intersubjetivas en torno a la definición de amenazas y objetos de seguridad. Estas expresiones pueden ayudar a cuestionar o reforzar conceptos dominantes en relación con la seguridad, basadas ya sea en la lógica realista, tales como el interés nacional, relaciones de poder o equilibrios de poder o amenazas, o en otros conceptos usados por reflectivistas moderados, sobre todo desde los debates en el seno de la comunidad regional, como es el caso de la seguridad cooperativa y humana, el interés y la agenda global, las relaciones de colaboración y concertación política, entre otros.

\section{COMENTARIOS FINALES}

Como hemos argumentado, el paso de nociones realistas a constructivistas da cuenta de que limitar la idea de seguridad a seguridad nacional o a seguridad del Estado frente a posibles agresiones externas en la actualidad, es cuestionable. Esto sucede en la medida que tales agresiones son definidas de forma compleja, y se consideren construcciones sociales, en ocasiones manipuladas por discursos de las elites o propuestas por comunidades epistémicas que tienen sus propios valores e intereses, sobre todo en contextos democráticos y de mayor distensión vecinal como ocurre hoy. Por ello, el supuesto de que dichas amenazas son claramente identificables, permanentes y objetivas es erróneo, pues son más bien subjetivas y responden a procesos de aprendizaje y reificación o naturalización de estructuras de ideas en el tiempo (Wendt, 2005; Salomón, 2002, p. 41).

La extensión del concepto seguridad a nuevas amenazas constituye un problema para los gobiernos con crisis de gobernabilidad (Tickner, 2008), como es el caso de América del Sur y particularmente en el Cono Sur, pues los lleva a securitizar la agenda y a la apelación de las 
FF.AA a responder a estos desafíos en ocasiones sin respetar procedimientos democráticos. No obstante que, como hemos visto, distintas comunidades epistémicas están alertando de este proceso de securitización (Griffiths, 2008; Orozco, 2006; Dammert y Bailey, 2005).

Por otro lado, con la pos Guerra Fría, además, se constata que la seguridad (humana) se puede garantizar desde el respeto a los DD.HH, la consolidación democrática y la gobernabilidad dando paso a crear comunidades de seguridad más o menos efectivas e institucionalizadas. Aunque se trate de un proceso inconcluso, sobre todo por el surgimiento de dinámicas contradictorias, pues paralela a la formación de estas comunidades persisten estrategias de securitización e instrumentalización de rivalidades vecinales. ${ }^{13}$

Si bien los intentos de crear estas comunidades en el Cono Sur han contribuido a crear nuevas identidades en torno a la institucionalización de la seguridad, la reificación de estructuras de ideas en torno a la seguridad nacional y la geopolítica instintiva dificulta este proceso de cambio pacífico en la región. Expresión de este proceso es la securitización de las rivalidades fronterizas heredadas, las cuales, empíricamente, no constituyen una amenaza concreta -en tanto hipótesis de conflicto bélico tradicional- habida cuenta de la interdependencia creciente de la región.

Por otro lado, la debilidad o incapacidad para dar soluciones a problemas sociales complejos de la región -asociados a la securitización de las nuevas amenazas pos guerra fría- es respondida por las autoridades en ocasiones a través de soluciones contingentes, apelando a la necesidad y urgencia, invocando la excepcionalidad y la emergencia asociada al decisionismo político ${ }^{14}$ (Negretto, 1994) y descuidando el debate democrático en torno a estos problemas objeto de securitización.

Finalmente, la persistencia de la geopolítica tradicional en la definición de la seguridad, resulta en parte de que en materia de toma de decisiones se invocan las percepciones de analistas basadas en ocasiones en experiencias anteriores (Sotomayor, 2007). Así, una experiencia actual, como los conflictos diplomáticos del Cono Sur por litigios pendientes ${ }^{15}$, les evoca una anterior situación vecinal marcada por la geopolítica tradicional. En efecto, el enfoque de las percepciones erradas se puede complementar con el de securitización, en la medida que "la visión del

13. Un caso muy claro es el intento por multilateralizar el problema de la mediterraneidad boliviana este año 2012 en el seno de la OEA.

14. El decisionismo sostiene que "las decisiones relevantes para la vida práctica, sea que consistan en la aceptación de valores, en la elección de un proyecto histórico de vida, o la elección de un enemigo, no son accesibles a una deliberación racional ni son capaces de suscitar un consenso motivado racionalmente" (citado en Negretto, 1994). Esta deliberación racional estaría anclada a los congresos o parlamentos y el decisionismo al soberano: el híper presidencialismo latinoamericano.

15. El litigio entre Chile y Perú por el límite marítimo evoca la Guerra del Pacífico; la demanda boliviana hacia Chile por la salida al Pacífico evoca el mismo conflicto; la ofensiva diplomática multilateral argentina por las Malvinas evoca la guerra de 1982 . 
otro -sustentadas a menudo en imágenes erróneas o preconceptos-, habrían influido en la formulación de las respectivas políticas externas, en particular sobre las relaciones bilaterales limítrofes" (Bernal-Meza, 2005, p. 278). Pues, aunque usualmente se cree lo contrario, los individuos no son tomadores de decisiones perfectamente racionales (Herrero, 2006).

No obstante, esta observación se debe matizar con las constricciones que impone la agenda regional y mundial en lo referido a solución pacífica de las controversias, énfasis en seguridad humana y los nuevos mecanismos en materia de seguridad cooperativa desde una perspectiva efectiva.

Es tarea de la opinión pública sudamericana incidir en los persistentes discursos de política de seguridad agresiva, mediante la intervención de varios actores no estatales y sobre todo desde comunidades epistémicas que promuevan la alteración del contexto normativo en el que las élites políticas conosureñas operan.

\section{BIBLIOGRAFÍA}

- Atkins. P. (1991). América Latina en el Sistema Político Internacional. Buenos Aires: Grupo Editorial latinoamericano.

- $\quad$ Adler, E. and Barnett, M. (1998). A Framework for the Study of Security Communities. En: Adler, E. and Barnett, M. (Eds.). Security Communities (29-66). Cambridge: Cambridge University Press.

- Adler, E. y Haas, P. (1992). "Conclusion: Epistemic Communities, World Order, and the creation of a Reflective Research Program". International Organization, 46 (1), 367-390.

- Álvarez, G. y Ovando, C. (2009). El Consejo de Defensa Suramericano: posibilidades de integración desde una perspectiva constructivista. Pap.polit. [Online], 14 (2) [citado 201205-02], 543-579. Recuperado de: <http://www.scielo.org.co/scielo.php?script=sci arttext\&pid=S0122-44092009000200009\&lng=es\&nrm=iso $>$. ISSN 0122-4409.

- Bernal-Meza, R. (2005). América Latina en el mundo. El pensamiento latinoamericano y la teoría de las relaciones internacionales. Buenos Aires: Nuevohacer, Grupo editorial latinoamericano.

- Buzan, B. (1991). People, States and Fear, An agenda for International Security Studies in the Post-Cold war era. Worcester: Harvester Wheatsheaf.

- Carrión Mena, F. (1998). Hacia una reformulación del concepto de la seguridad continental. Revista Fuerzas Armadas y Sociedad, 13 (3), 18-23. 
- $\quad$ Corlazzoli, J. P. (1978). Estructuración e ideología de los regímenes militares en América Latina, los casos de Brasil, Chile y Uruguay. Tesis de Licencia en Sociología. Lovaina: U. Católica de Lovaina.

- Dammert, L. y Bailey, J. (2005). Reforma policial y participación militar en el combate a la delincuencia. Análisis y desafíos para América Latina. Revista Fuerzas Armadas y Sociedad, 19 (1), 133-152.

- $\quad$ Der Derian, J. (1987). On Diplomacy: A Genealogy of Western Estrangement. Oxford: Blackwell.

- Devés, E. (2003). El pensamiento latinoamericano en el siglo XX. Desde la Cepal al neoliberalismo (1950-1990). Tomo II. Santiago: Biblos, Centro de Investigaciones Barros Arana.

- $\quad$ Fermandois J. (2004). Mundo y fin de mundo: Chile en la política mundial 1900-2004. Santiago: Ediciones Universidad Católica de Chile.

- $\quad$ Fernandois, J. y León Hulaud, M. (2005). "¿Antonimia entre democracia y gobierno militar? Chile y Argentina en el momento de incertidumbre (1955 -1973)". En: Lacoste, Pablo (editor), 2005. Argentina, Chile y sus Vecinos, Tomo II, Caviar Bleu, Mendoza-Argentina, pp. 93-141.

- $\quad$ Flemes, D. (2003). Respuestas del MERCOSUR a las amenazas transnacionales. Revista Fuerzas Armadas y Sociedad, (1), 141-161.

- $\quad$ Flemes, D. (2003). Seguridad cooperativa en el sur de América Latina - Una propuesta teórica. Ponencia en el $51^{\circ}$ Congreso Internacional de Americanistas. Santiago. Manuscrito.

- Flemes, D., Nolte, D. y Wehner, L. (2011). Una comunidad de seguridad regional en formación: la UNASUR y su Consejo de Defensa. Estudios Internacionales, 170, 105-127.

- $\quad$ García, C. y Ángel, R. (eds.) (2008). La necesidad de redefinir la seguridad: seguridad humana, seguridad colectiva y derecho internacional. La seguridad comprometida. Nuevos desafíos, amenazas y conflictos armados (205-228). Barcelona: Tecnos.

- $\quad$ Forsberg, R. (1995). La creación de un sistema global de seguridad cooperativa. Revista Fuerzas Armadas y Sociedad, 10 (4), 1-9.

- $\quad$ Fuchs, R. (2006). ¿Hacia una comunidad regional de seguridad?: las fuerzas armadas en la percepción de las elites parlamentarias en argentina, Brasil, Chile, Paraguay y Uruguay. Revista Ciencia. Política, 26 (2), 29-52. 
- Fuentes, C. (2008). Fronteras calientes. Foreign Affairs Latinoamérica, 8 (3), 12-21.

- Griffiths, J. (2008). Seguridad hemisférica en América Latina. Alcances y proposiciones. Escenarios Actuales, 13, 13-26.

- Herranz, A. (2009). Muchos mundos, muchas Europas: el postmodernismo en las Relaciones Internacionales y los Estudios Europeos. En: Documentos CIDOB, Dinámicas interculturales. Barcelona: Fundación CIDOB, 14,47-56

- Herrero de Castro, R. (2006). La realidad inventada. Percepciones y proceso de toma de decisiones en política exterior. Madrid: Plaza Valdés.

- Hopf, T. (1998). The promise of constructivism in International Relations theory. International Security, 23 (1), 171-200.

- Hurrell, A.ndrew (1998). Security in Latin America. International Affairs, 74 (3),529-546

- Jervis, R. (1976). Perception and Misperception in Internationals Relations. Princeton: Princeton University Press.

- $\quad$ Kurtenbach, S. (2001). Tendencias de las políticas de seguridad en América Latina al principio del siglo XXI. Revista Fuerzas Armadas y Sociedad, 16 (2), 3-14.

- $\quad$ Keohane, R. y Nye, J. (1988). Poder e interdependencia. La política mundial en transición. Buenos Aires: GEL.

- Lacoste, P. (2003). Actores no estatales de frontera y relaciones internacionales: el caso de de los andes centrales argentino chilenos. Revista Estudios tranfronterizos, 1, (1), 77-130

- $\quad$ Laïdi, Z. (1997). Un mundo sin sentido. México: Fondo de Cultura Económica

- Leal, F. (1992). Surgimiento, auge y crisis de la Doctrina de Seguridad Nacional en América latina y su aplicación en Colombia. Análisis Político, (15), 6-34.

- Leyton, C. (2007). Amigos y vecinos en la costa del Pacífico. Luces y sombras de una relación. Santiago: ANEPE.

- Leyton, C. (2005). Instrumentalización de conflictos históricos: el caso chileno-boliviano. Revista Política y Estrategia, 97, 9-26.

- López, E. (2000). ¿Un sistema subregional de seguridad? Revista Fuerzas Armadas y Sociedad, 15 (4), 38-50. 
- McDonald, M. (2008). Constructivism and security. En: Paul D. Williams (Ed.), Security studies: An introduction (59-67). London: Routledge.

- Michelena, A. (1995). Hacia una nueva visión de la seguridad en el Continente Americano: del temor a la confianza. Revista Fuerzas Armadas y Sociedad, 10 (3), 20-34.

- Negretto, G. (1994). El concepto de decisionismo en Carl Schmitt. Revista Sociedad 4,66-89.

- $\quad$ Nogues Zubizarreta, H. (1998). Seguridad y fomento de la confianza. Revista Fuerzas Armadas y Sociedad, 13 (1), 52-54.

- Orozco, G. (2006). El aporte de la Escuela de Copenhague a los estudios de seguridad. Revista Fuerzas Armadas y Sociedad, 20 (1), 141-161.

- $\quad$ Orozco, G. (2008). ¿Es posible un Complejo de seguridad en la región andina? Un análisis desde los aportes de la Escuela de Copenhague. Ponencia para el Primer Congreso de Ciencia Política, Asociación Colombiana de Ciencia Política ACCPOL. Bogotá.

- $\quad$ Ovando, C. y Álvarez, G. (2011). La dimensión fronteriza de la política exterior de Chile: inmovilidad y emergencia de nuevas dinámicas. Estudios Fronterizos, Nueva Época, 12 (24), 75-102.

- $\quad$ Ovando, C. (2009). Hacia la complementariedad Realismo-Liberalismo: aproximación a las relaciones chileno bolivianas desde debate ideas claves y factores materiales. Revista Enfoques, 10, 235-271.

- $\quad$ Pérez Gil, L. (2000). La persistente vigencia del enfoque realista en el estudio de la seguridad nacional, en las relaciones internacionales de la posguerra fría. Política y Estrategia, 81, 73-90.

- Peters, G. (2003). El nuevo institucionalismo. Teoría institucional en ciencia política. Madrid: Gedisa.

- $\quad$ Rojas, F. y Robledo, M. (2002). Construyendo un régimen cooperativo de seguridad en el Cono Sur de América Latina. Elementos conceptuales, políticos y estratégicos. Revista Fuerzas Armadas y Sociedad, 17 (1-2), 5-31.

- Rojas, F. (2000). Repensando la seguridad en América Latina: nuevas demandas conceptuales. Revista Fuerzas Armadas y Sociedad, 15 (2), 3-13. 
- Russell R. y Tokatlian, J. (2002). De la autonomía antagónica la autonomía relacional: una mirada teórica desde el Cono Sur. Perfiles Latinoamericanos, 21, 159-194

- Salgado, J. e Izurieta, O. (1992). Las relaciones bilaterales chileno-peruanas contemporáneas: un enfoque realista. Santiago: Olimpho

- Salomón, M. (2002). La Teoría de las Relaciones Internacionales en los Albores del Siglo XXI: Diálogo, Disidencia y Aproximaciones. Revista Electrónica de Estudios Internacionales, 4. Recuperado de: www.reei.org.

- Smith, S. (1995). The Self-Images of a Discipline: a Genealogy of International Relations Theory. En K. Booth \& S. Smith (eds.), International Relations Theory Today. Cambridge: Polity Press.

- Sodupe, K. (2003). La teoría de las relaciones internacionales a los inicios del siglo XXI. Gipuzkoa: Servicio editorial de la Universidad del País Vaco.

- Sotomayor, A. (2007). La seguridad internacional: vino viejo en botellas nuevas. Revista Ciencia política, 27 (2), 67-88.

- Subercaseaux, B. (2006). La cultura en los gobiernos de la concertación. Universum, 21 (1), 190-203.

- Taylor, H. (1987). Análisis geopolítico de las Falklands. Revista chilena de geopolítica, 3 (3), 42-64.

- Tickner, A. (2008). Los estados y la securitización: dinámicas de seguridad andina. Ponencia presentada al Primer Congreso de Ciencia Política. Bogotá, septiembre 30-octubre 4.

- Tomassini, L. (1989). Teoría y Práctica de la Política Internacional. Santiago: Ediciones Universidad Católica.

- Walt, S. (1985). Alliance formation and the balance of world politics. International Security, $9(4), 1-42$.

- Waltz, K. (1979). Teoría de la Política Internacional. Buenos Aires: GEL.

- Wendt, A. (2005). La Anarquía es lo que los Estados hacen de ella. Revista Académica de Relaciones Internacionales, 1 (1) , 1-47

- Wæver, O. (1995). Securitization and Desecuritization. En R. Lipschutz (ed.), On Security (46-48). New York: Columbia University Press. 
- Witker, I. (2000). Los conceptos interés nacional y regionalismo abierto en el acercamiento Chile/ MERCOSUR. Política y Estrategia, 82, 125-137.

- Witker, I. (2010). Bandwagoning. Algunas claves para entender los problemas de integración hemisférica. Escenarios Actuales, Junio, año 15, 1, 5-11

- Zepeda, J. (2006). ¿Son los movimientos indígenas un impacto para la Seguridad Nacional, Escenarios Actuales, Junio, año 11, 4, 12-21

\section{FUENTES ELECTRÓNICAS}

- "Gobernador Rojas propone socializar "fiscalización amigable" a buses bolivianos". Diario el 21, lunes 28 de marzo de 2011.Consultado el 24 de noviembre de 2012. ( http:// diario21.cl/ediciones/pdf21 marzo28.pdf)

- MERCOSUR(1992) "Documentos oficiales". Montevideo, Uruguay. Piera, Luis. Consultada el 24 de noviembre de 2012 (http://www.mercosur.int/home.jsp?contentid= $\underline{7 \& \text { seccion }=1)}$

- $\quad$ Centro de Estudios e Investigaciones Militares, Santiago de Chile, Toledo Marina, Consultada el 24 de noviembre de 2012 (http://www.cesim.cl/)

- Academia Nacional de Estudios Políticos y Estratégicos, Ministerio de Defensa Nacional de Chile. Santiago de Chile. Consultada el 24 de noviembre de 2012(http://www.anepe.cl)

- $\quad$ Revista Fuerzas Armadas y Sociedad, FASOC. Facultad Latinoamericana de Ciencias Sociales, FLACSO Chile. Santiago de Chile. Consultada el 24 de noviembre de 2012 (http:/ (www.fasoc.cl/php/fasoc.php)

- $\quad$ Diario el 21, "Gobernador Rojas propone socializar "fiscalización amigable" a buses bolivianos". 


\section{ANEXO \\ ALGUNOS ENFOQUES TEORICOS REFERIDOS AL DEBATE SOBRE SEGURIDAD INTERNACIONAL EN CHILE}

\begin{tabular}{|c|c|c|c|c|}
\hline $\begin{array}{l}\text { Enfoques teóri- } \\
\text { cos de seguri- } \\
\text { dad presentes } \\
\text { en Cono Sur }\end{array}$ & $\begin{array}{l}\text { Realismo y } \\
\text { neorrealismo }\end{array}$ & $\begin{array}{l}\text { Constructivismo y } \\
\text { Comunidades de } \\
\text { Seguridad }\end{array}$ & $\begin{array}{l}\text { Seguridad Hu- } \\
\text { mana }\end{array}$ & Securitización \\
\hline $\begin{array}{l}\text { Principales } \\
\text { actores }\end{array}$ & El Estado & $\begin{array}{l}\text { Conjunto de Esta- } \\
\text { dos y la Sociedad } \\
\text { civil Internacional } \\
\text { Regímenes inter- } \\
\text { nacionales regio- } \\
\text { nales }\end{array}$ & $\begin{array}{l}\text { Conjunto de Es- } \\
\text { tados y la Socie- } \\
\text { dad civil Inter- } \\
\text { nacional } \\
\text { Regímenes inter- } \\
\text { nacionales regio- } \\
\text { nales }\end{array}$ & El Estado \\
\hline $\begin{array}{l}\text { Objetivos } \\
\text { de seguridad }\end{array}$ & $\begin{array}{l}\text { Integridad te- } \\
\text { rritorial. } \\
\text { Supervivencia } \\
\text { del Estado }\end{array}$ & $\begin{array}{l}\text { Convivencia pací- } \\
\text { fica subregional. } \\
\text { Concertación po- } \\
\text { lítica subregional }\end{array}$ & $\begin{array}{l}\text { Bienestar del ciu- } \\
\text { dadano } \\
\text { Limitar la inje- } \\
\text { rencia del Estado } \\
\text { como fuente de } \\
\text { inseguridad del } \\
\text { ciudadano }\end{array}$ & $\begin{array}{l}\text { Integridad terri- } \\
\text { torial } \\
\text { Supervivencia } \\
\text { del Estado }\end{array}$ \\
\hline $\begin{array}{l}\text { Principales } \\
\text { amenazas }\end{array}$ & $\begin{array}{l}\text { Litigios fronte- } \\
\text { rizos pendien- } \\
\text { tes } \\
\text { Enemigo in- } \\
\text { terno (década } \\
\text { del } 70 \text { y } 80 \text { ) }\end{array}$ & $\begin{array}{l}\text { Nuevas amena- } \\
\text { zas: deterioro me- } \\
\text { dio ambiente, po- } \\
\text { breza, terrorismo, } \\
\text { narcotráfico, crisis } \\
\text { de gobernabilidad } \\
\text { interna, crimen } \\
\text { organizado trans- } \\
\text { nacional }\end{array}$ & $\begin{array}{l}\text { Pobreza, crisis } \\
\text { económicas, de- } \\
\text { terioro medio } \\
\text { ambiente, crisis } \\
\text { de gobernabi- } \\
\text { lidad }\end{array}$ & $\begin{array}{l}\text { Instrumentali- } \\
\text { zación de los li- } \\
\text { tigios fronte- } \\
\text { rizos } \\
\text { Securitización } \\
\text { de la delincuen- } \\
\text { cia en ámbito } \\
\text { doméstico }\end{array}$ \\
\hline $\begin{array}{l}\text { Comunidades } \\
\text { epistémicas } \\
\text { presentes } \\
\text { en Chile }\end{array}$ & $\begin{array}{l}\text { CESIM } \\
\text { ANEPE }\end{array}$ & $\begin{array}{l}\text { FLACSO: Progra- } \\
\text { ma FF.AA y Socie- } \\
\text { dad ANEPE }\end{array}$ & $\begin{array}{l}\text { FLACSO: Pro- } \\
\text { grama FF.AA y } \\
\text { Sociedad CESIM } \\
\text { ANEPE }\end{array}$ & $\begin{array}{l}\text { FLACSO: Pro- } \\
\text { grama FF.AA y } \\
\text { Sociedad }\end{array}$ \\
\hline
\end{tabular}

Fuente: Elaboración propia. 